\title{
Premature termination mutations in exon 3 of the SMN1 gene are associated with exon skipping and a relatively mild SMA phenotype
}

\author{
Vittorio Sossi ${ }^{1}$, Anna Giuli ${ }^{1}$, Tiziana Vitali ${ }^{1}$, Francesco Tiziano ${ }^{1}$, Massimiliano Mirabella ${ }^{2}$, \\ Antonella Antonelli ${ }^{3}$, Giovanni Neri ${ }^{1}$ and Christina Brahe ${ }^{*, 1}$
}

${ }^{1}$ Institute of Medical Genetics, Catholic University, Rome, Italy; ${ }^{2}$ Department of Neurology, Catholic University,
Rome, Italy; ${ }^{3}$ Medical Genetics, Department of Internal Medicine and Public Health, University of Aquila, Aquila,
Italy

Autosomal recessive spinal muscular atrophy (SMA) is a common motor neuron disease caused by absence or mutation in the survival motor neuron (SMN1) gene. SNM1 and a nearly identical copy, SMN2, encode identical proteins, but $S M N 2$ only produces a little full length protein due to alternative splicing. The level of functional SMN protein and the number of SMN2 genes correlate with the clinical phenotype ranging from severe to very mild. Here, we report on premature termination mutations in SMN1 exon 3 (425del5 and W102X) which induce skipping of the mutated exon. The novel nonsense mutation W102X was detected in two patients with a relatively mild phenotype who had only two copies of the SMN2 gene, a number that has previously been found associated with the severe form of SMA. We show that the shortened transcripts are translated into predicted in frame protein isoforms. Aminoglycoside treatment suppressed the nonsense mutation in cultured cells and abolished exon skipping. Fibroblasts from both patients show a high number of nuclear structures containing SMN protein (gems). These findings suggest that the protein isoform lacking the exon 3 encoded region contributes to the formation of the nuclear protein complex which may account for the milder clinical phenotype. European Journal of Human Genetics (2001) 9, 113-120.

Keywords: spinal muscular atrophy; survival motor neuron gene; exon skipping; mutations

\section{Introduction}

Proximal spinal muscular atrophy (SMA) is one of the most frequent autosomal recessive diseases with an estimated incidence of 1 in 10000 live births. It is a motor neuron disorder characterised by the degeneration of spinal cord anterior horn cells which results in weakness of proximal limb and trunk muscles. Based on the age of onset and severity of the clinical course, childhood onset SMAs can be classified into three types. ${ }^{1}$ Type I is the most severe form with onset ranging from prenatally to 6 months of life; the

*Correspondence: Dr Christina Brahe, Istituto di Genetica Medica, Università Cattolica, Largo F. Vito, 1, I-00168 Roma, Italy. Tel: +3906355 00877; Fax: +39 06305 0031; E-mail: cbrahe@rm.unicatt.it Received 4 August 2000; revised 29 September 2000; accepted 10 October 2000 children are never able to sit without support. Type II is an intermediate form with onset before the age of 18 months; the patients are unable to stand or walk. Type III is a relatively mild, chronic form with onset after the age of 18 months.

All three forms of SMA are caused by absence or mutation of the survival motor neuron (SMN1) gene localised to chromosome $5 \mathrm{q} 13 .^{2}$ This region contains a second gene (SMN2) which is nearly identical to SMN1 but can be distinguished from it by two base changes in exons 7 and $8 .^{2}$ It has recently been demonstrated that the synonymous C-to-T transition in exon 7 is responsible for alternative splicing of exon 7 of the SMN2 transcripts. ${ }^{3,4}$ Hence, the two genes generate different proportions of full length transcripts: SMN1 produces primarily full-length transcripts, whereas SMN2 produces primarily transcripts lacking exon 7 plus minor amounts of full length transcripts and 
transcripts lacking exon 5 or both exon 5 and exon $7 .^{2,5}$ It has been shown that the protein product of the alternatively spliced transcripts is less stable and functionally defective. ${ }^{6}$ Thus, SMA is caused by reduced levels of functional protein. ${ }^{7}$ Recently, we and others have shown that the clinical severity is influenced by the copy number of SMN2 genes. ${ }^{8-10}$

The great majority of SMA patients show homozygous absence of SMN1 caused by deletion or gene conversion. ${ }^{2,11}$ Subtle mutations in SMN1 are relatively rare. The 23 different mutations described so far are distributed all over the gene but are more frequently found at the $3^{\prime}$ end. ${ }^{12}$ There is no strict correlation between the type of mutation and the clinical phenotype. For unrelated compound heterozygotes with identical missense or frameshift mutations the difference in phenotypic expression can often, but not always, be explained by the different number of SMN2 genes. ${ }^{13,14}$

The SMN protein is part of a large protein complex and is localised in both the cytoplasm and in the nucleus. In the cytoplasm SMN plays a role in the biogenesis of spliceosomal small nuclear riboproteins (snRNPs). ${ }^{15}$ In the nucleus SMN appears concentrated in a few dot-like structures, designated gems, ${ }^{16}$ where it is involved in pre-mRNA splicing. ${ }^{17}$ Immunofluorescence analysis of different cell types has shown that the number of gems is markedly reduced in SMA patients. ${ }^{9,18}$

The SMN protein comprises several functionally important domains. The N-terminus interacts directly with a novel protein, Gemin2, whereas the C-terminal part is involved in oligomerisation and binding of a novel DEAD box protein, Gemin3. ${ }^{19}$ The C-terminus has also been implicated in interacting with several snRNP Sm proteins. ${ }^{15}$ In contrast, Bühler $e t a l^{20}$ have reported that the central region of SMN is necessary and sufficient for binding Sm proteins. This central region is encoded by exon 3 and encompasses a tudor domain which is present in proteins with RNA binding function. ${ }^{21}$

Here, we report on patients with mutations in SMN1 exon 3 leading to premature termination codons and skipping of the entire exon. The shortened transcripts are translated into protein isoforms which can be included into the nuclear protein complex, as suggested by the particularly high number of gems detected in fibroblasts of these patients. The production of these protein isoforms probably explains the relatively mild phenotype of these patients.

\section{Material and methods \\ Patients}

We studied three patients with clinical diagnosis of SMA including EMG and muscular biopsy. For all three patients both DraI digestion of PCR products and SSCP analysis showed the presence of $S M N 1$ exon 7. Patient PA is a girl aged 2 years and 9 months with SMA type I. She suffered from periodic respiratory crisis but is neither intubated nor ventilated artificially, thus representing an attenuated expression of SMA I. Patient ZE is a 19-year-old young man and has a clinical phenotype typical of SMA type II. Patient DG, is a 24-year-old mother of a 2-year-old healthy girl and presently at her second pregnancy. She is a type III patient and walks mostly with support.

Primary fibroblast lines from skin biopsies and lymphoblastoid cell lines were established from patients ZE and DG.

\section{RT - PCR}

Total RNA was isolated from peripheral blood leucocytes, fibroblast and lymphoblastoid cell lines using Trizol (GIBCO BRL, Grand Island, NY, USA), according to the instructions of the manufacturer. First-strand cDNA synthesis was performed as previously described. ${ }^{22}$ In some experiments SMN cDNA isoforms were amplified together with a 390-bp partial MLH1 cDNA, employed as internal standard, in a multiplex PCR reaction.

\section{Cloning of cDNAs and genomic DNA}

Single strand cDNAs were amplified with $300 \mathrm{~nm}$ of each primer SMNpro-F (5'- TGC GCA TCC GCG GGT TTG CTA $\mathrm{T}-3^{\prime}$ ) in $5^{\prime}$ UTR and $c 770^{2}$ in exon $7,200 \mu \mathrm{M}$ each dNTPs, $1 \times$ expand $\mathrm{HF}$ buffer, $1.5 \mathrm{mM} \mathrm{MgCl}_{2}$ and $2.6 \mathrm{U}$ Expand High Fidelity Polymerase (Boehringer Mannheim), in a final reaction volume of $100 \mu \mathrm{l}$; annealing temperature was $60^{\circ} \mathrm{C}$.

Genomic DNA of patients was amplified with $1 \mu \mathrm{M}$ of each primer 2BF2 (5'- AGA GCT GAT GTC AGG TGT AT -3') in intron $2 \mathrm{a}$ and EX4R (5'- GAG AGG TTA AAT GTC CCG AC -3') in intron 4, $200 \mu \mathrm{M}$ dNTPs, $2 \mathrm{mM} \mathrm{MgCl}_{2}, 1 \mathrm{U}$ of Taq polymerase (Boehringer Mannheim); annealing temperature was $55^{\circ} \mathrm{C}$.

Of both PCR products, 20 ng were cloned into the pCRIITOPO cloning vector (Invitrogen), according to the manufacturer's protocol. Colonies derived from cDNAs were analysed by PCR with primers X7DRA ${ }^{23}$ and $\mathrm{C}^{2} 18^{2}$ and digested with $6 \mathrm{U}$ of DraI (New England Biolabs) to select SMN1 and SMN2 clones. A minimum of six SMN1 cDNA colonies and 15 genomic colonies were cultured, DNA was purified and sequenced with Dye Terminator Cycle Sequencing kit (PE Applied Biosystems) according to the manufacturer's instructions by using both vector and internal primers.

The W102X and S139S mutations were confirmed on colonies, genomic DNA and cDNA by PCR amplification, respectively, with specific primers SMN3Stop forward (5'GGG ACA AAT GTT CTG CCA CTT -3') and SMN3Dde reverse (5'- CAC AGA TTG GGG AAA GTA GCT C -3'): these primers introduce DdeI restriction sites in mutated templates only. Cycling conditions consisted of an initial denaturation step at $95^{\circ} \mathrm{C}$ for $10 \mathrm{~s}, 32$ cycles at $95^{\circ} \mathrm{C}$ for $30 \mathrm{~s}, 58^{\circ} \mathrm{C}$ for $30 \mathrm{~s}, 72^{\circ} \mathrm{C}$ for $20 \mathrm{~s}$ and a final extension step of $3 \mathrm{~min}$ at $72^{\circ} \mathrm{C}$, followed by overnight digestion of $10 \mu \mathrm{l}$ of PCR products with $3 \mathrm{U}$ of DdeI (New England Biolabs) and electrophoresis on 2\% TBE $1 \times$ agarose gel. 


\section{Southern blot analysis}

Approximately $8 \mu \mathrm{g}$ of genomic DNA of patients were digested with EcoRI and migrated on a $0.8 \%$ TBE $1 \times$ agarose gel. Probes and hybridisation protocol were previously described. $^{8}$

\section{Study of exon skipping}

cDNAs from leukocytes of patients of the present study, 11 SMA patients of various clinical phenotype, and 22 unaffected controls were amplified by standard PCR (35 cycles) reaction with $1.5 \mathrm{~mm} \mathrm{MgCl}_{2}$. Primer pairs used were SMNPro-F/C770 and/or SMNPro-F/EX4R2 (5' - TCC ATG GAG CAG ATT TGG GCT TG -3') in exon 4.

cDNAs from fibroblast and lymphoblastoid cells of patients and controls were studied by radioactive PCR. Three separate low-number-cycle (22 cycles) radioactive PCRs were performed with primers SMNPro-F and C770 as described above except that $0.1 \mu \mathrm{l} \alpha$-dCTP (NEN Life Science Products) was added. PCR products were electrophoresed in a $4 \%$ acrylamide TBE $0.6 \times$ Urea $6 \mathrm{~m}$ gel for $3 \mathrm{~h}$ at $35 \mathrm{~W}$. Gels were exposed overnight on a Cyclone Storage Phosphor System (Packard Instrument Company) and densitometric analysis was performed (OptiQuant software). Average percentage of $-3 /+7$ over the total of $-3 /+7$ plus $+3 /+7$ isoform PCR products for each sample were calculated.

\section{Western blot analysis}

Western blot analysis was performed as described elsewhere ${ }^{18}$ with the exception that the commercial anti-SMN was used as primary antibody.

\section{FISH}

Fluorescence in situ hybridisation (FISH) was performed on interphase nuclei preparations as previously described. ${ }^{8}$

\section{Quantitative PCR}

SMN1 copy-number assay was performed as described by Wirth et $a l^{14}$ with the exception that radioactive PCR was used and that acrylamide gels were exposed on the Cyclone Storage Phosphor System.

\section{Analysis of SMN2 isoforms}

cDNAs of patients and controls were amplified using primers SMNPro-F and $\mathrm{C} 1120^{2}, 124$ nt downstream the DdeI restriction site in SMN2; cycling conditions consisted of an initial denaturation step at $94^{\circ} \mathrm{C} 10 \mathrm{~s}$, followed by 35 cycles at $94^{\circ} \mathrm{C}$ for $1 \mathrm{~min}, 60^{\circ} \mathrm{C}$ for $1 \mathrm{~min}, 72^{\circ} \mathrm{C}$ for $2 \mathrm{~min}$ and a final extension step of $3 \mathrm{~min}$ at $72^{\circ} \mathrm{C}$. Ten $\mu$ l of PCR were digested overnight with $3 \mathrm{U}$ of DdeI and electrophoresed on a $2 \%$ TBE $1 \times$ agarose gel. Band intensity was investigated by direct densitometric analysis of the gels using Gel Doc 2000 System (BIO-RAD). Percentage of SMN2 full length (fl) was deduced from the ratio between $S M N 2 \mathrm{fl}$ and the total of $S M N 2 \mathrm{fl}$ plus - 7 SMN2 isoforms. Average values were obtained from three different PCR experiments.

\section{Immunofluorescence analysis}

Immunofluorescence studies of the SMN protein were performed on fibroblasts of patients and controls as previously described. ${ }^{18}$ The protein was detected by using the commercial anti-SMN monoclonal antibody (Transduction Laboratories) and the $2 \mathrm{~B} 1$ antibody, ${ }^{16}$ kindly provided by Dr G Dreyfuss. Each experiment was performed three times.

\section{Aminoglycoside treatment}

In preliminary tests fibroblasts and lymphoblastoid cells were incubated with medium (BioAmf and RPMI, respectively) supplemented with increasing concentrations (50, 100 and $200 \mu \mathrm{g} / \mathrm{ml}$ ) of Geneticin G-418 sulphate (GIBCO BRL) as previously described. ${ }^{24}$ At the concentration of $200 \mu \mathrm{g} / \mathrm{ml}$ fibroblasts died within $48 \mathrm{~h}$, whereas at $100 \mu \mathrm{g} / \mathrm{ml}$ or less cells were viable for at least 1 week. For transcript analysis, RNA was extracted from lymphoblastoid cells and fibroblasts treated for $48 \mathrm{~h}$ with $50 \mu \mathrm{g} / \mathrm{ml}$ and $100 \mu \mathrm{g} / \mathrm{ml} \mathrm{G}-418$, respectively. For protein analysis, cells were treated for $72 \mathrm{~h}$ with above indicated concentrations of G-418.

\section{Results}

Mutations and exon 3 skipping

Standard SSCP analysis of SMN exon 7 from the type II (ZE) and the type III (DG) patient revealed an abnormal pattern of migration. Sequencing of exon 7 and adjacent intron junctions showed an A-G transition 96 nt upstream from the exon 7 start site for both patients which has been described before as a rare polymorphism. ${ }^{25}$ Since SMN1 exon 7 specific bands were absent, we postulated that the two patients are compound heterozygotes and that the A-G base substitution is associated with a mutation elsewhere in the SMN1 gene.

Sequencing of genomic DNA of all exons did not show any apparent difference with respect to the wild-type sequence. However, by RT-PCR of the SMN mRNA, shortened transcripts were found for both patients (Figure 1). Sequence analysis of these shortened cDNAs showed a deletion of exon $3(-3)$ which does not lead to a shift in the translational reading frame. No mutation at the exon 3 splice sites could be detected. Also, deletion of exon 3 in the genomic DNA was excluded by Southern blot analysis (data not shown). We therefore cloned and sequenced RT - PCR products comprising the complete coding region. A G-A transition at base 305 of the coding sequence was detected in several clones from both patients (Figure 2a). This previously unreported mutation alters a tryptophan residue to a translational termination codon (W102X) in exon 3 of the SMN1 gene. The presence of this base substitution was confirmed by cloning and sequencing genomic DNA and by digestion of amplified genomic DNA and cDNA with DdeI by using a specific primer which creates the restriction enzyme site in the mutated DNA. A second mutation was detected in SMN1 
exon 3 of patient DG, which is a synonymous third base substitution TCC-TCT (S139S) (Figure 2b).

Sequence analysis of the DNA of patient PA (attenuated SMA I) revealed a 5-bp deletion (425del5) in exon 3 of SMN1 in the genomic DNA and cloned cDNAs (Figure 2c). The same mutation, which predicts a premature stop codon four nucleotides downstream, was described before for an unrelated very severely affected patient. ${ }^{22}$ Shortened transcripts lacking exon 3 were found in RT - PCR products also from this patient's mRNA (Figure 1).

The finding of skipping of exon 3 in a proportion of transcripts from all three patients with mutations in the same exon has led us to postulate that exon skipping was induced by the mutations. To investigate whether the transcripts lacking exon 3 originated from the mutated SMN1 gene we have analysed 15 cloned cDNAs from leukocyte mRNA of patient ZE by DraI restriction digestion and in part by

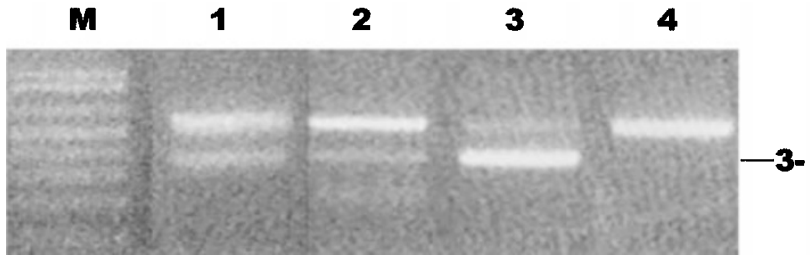

Figure 1 Detection of -3 isoforms. Agarose gel showing cDNA amplification products from SMN exons 1-4 obtained from peripheral blood leukocyte RNA. Transcripts lacking exon 3 were observed for patients PA (lane 1), ZE (lane 2) and DG (lane 3) but not for a control (lane 4). M: DNA size marker. sequence analysis. Six clones contained SMN1 transcripts, of which four had the W102X mutation and two lacked exon 3, whereas nine clones had SMN2 transcripts, which had retained a normal exon 3. Moreover, the PCR product obtained by re-amplification of a gel-extracted -3 cDNA from patient DG with X7Dra primer was found resistent to DraI enzyme digestion, providing further evidence that the shortened transcripts are derived from the SMN1 gene. RTPCR of mRNA from peripheral blood leukocytes or lymphoblastoid cells of 22 controls and 11 patients of SMA types I-III did not show isoforms lacking exon 3 . These findings suggest that skipping of exon 3 in a proportion of SMN1 transcripts from our patients is induced by the mutations which are distant from the splice junction consensus sequences.

Transcripts lacking exon 3 were also detected in mRNA from fibroblasts and lymphoblastoid cells from patients ZE and DG. The extent of exon skipping was 39 and 44\% (-3/ total transcripts; see Material and methods) in fibroblast mRNA of patients ZE and DG, respectively, but was less in lymphoblastoid cells (23\%) of patient DG.

\section{Shortened protein isoforms detected by Western blot}

To investigate whether the transcripts lacking exon 3 are translated into protein isoforms we performed Western blot analysis on extracts of fibroblasts and/or lymphoblastoid cells from patients ZE and DG. The anti-SMN antibody detected a $38-\mathrm{kDa} S M N$ protein, which should comprise full length and - 7 SMN2 gene products, and two shortened SMN protein isoforms (Figure 3). The molecular mass of approximately $31 \mathrm{kDa}$ of the smallest isoform corresponds to that $\mathbf{a}$

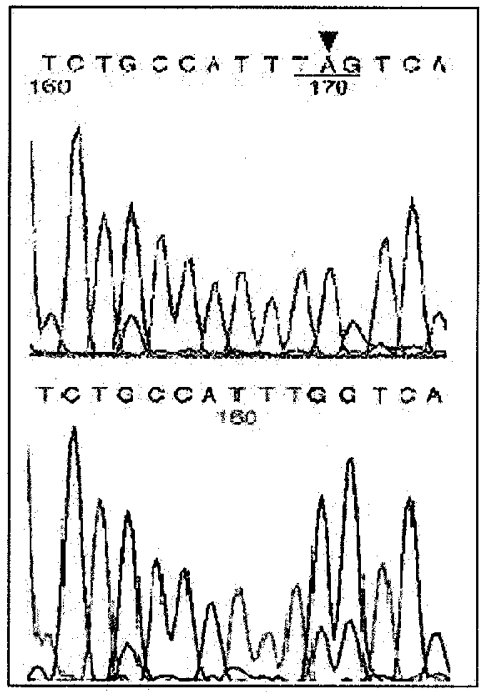

b

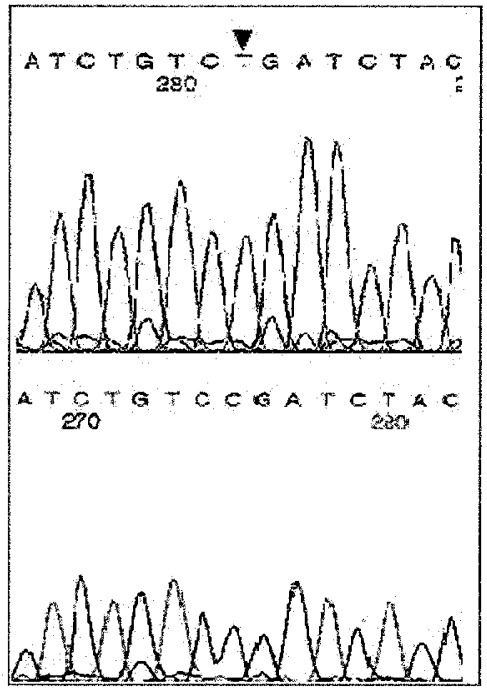

c

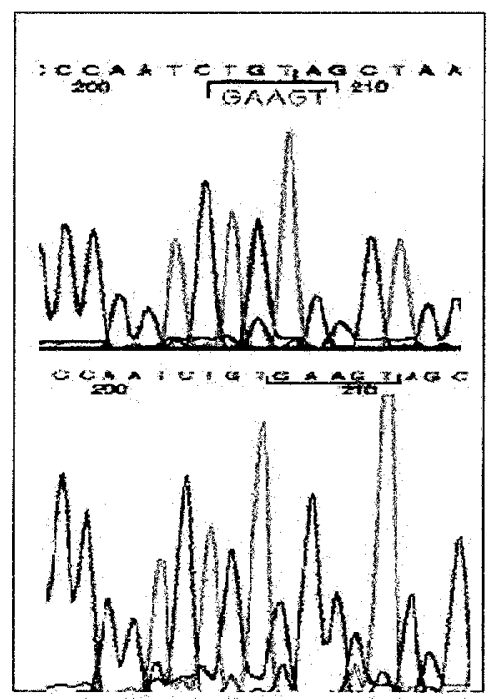

Figure 2 Mutations in SMN exon 3. Partial sequences of cloned genomic DNA showing the mutations (arrows) in the top panel compared to the wild-type sequence in the lower panel. (a) G-A transition at base 305 which alters a tryptophan residue to a translational termination codon (W102X) detected in patients ZE and DG. (b) Silent C-T substitution at codon 139 present in patient DG. (c) Deletion of $5 \mathrm{bp}$ (472del) found in DNA of patient PA. 


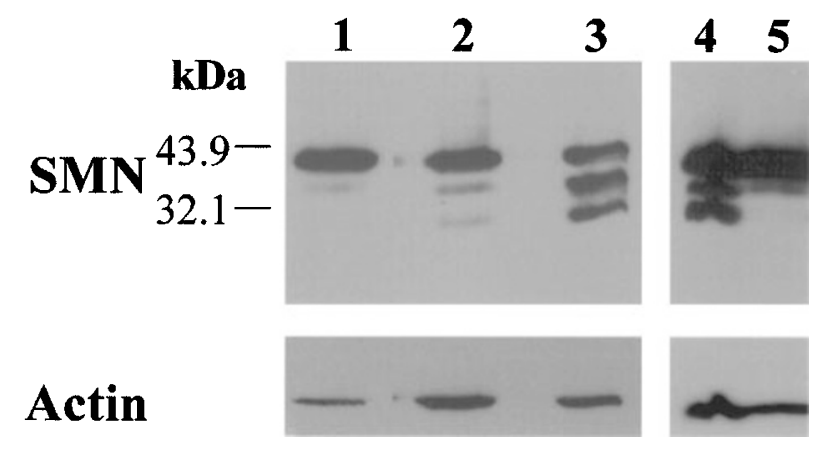

Figure 3 SMN protein isoforms. Western blot of SMN and actin in extracts from fibroblasts (lanes $1-3$ ) and lymphoblastoid cells (lanes 4 and 5 ). The anti-SMN antibody detects an SMN protein of approximately $38 \mathrm{kDa}$ and two smaller isoforms in the extracts of patients ZE (lane 3) and DG (lane 4) which are absent or negligible in the extracts of a SMA typel/II patient (lane 2) and controls (lanes 1 and 5).

expected for an SMN protein lacking the 67 aminoacids $(7.48 \mathrm{kDa})$ of exon 3 . The origin of the isoform of intermediate molecular weight is unknown.

\section{SMN gene copy analysis}

To establish whether the diverse clinical severity of the patients could be ascribed to a difference in the SMN2 copy number we performed FISH analysis on interphase nuclei. In the preparations of all three patients we found in $G_{1}$ phase nuclei one and two SMN signals, respectively, close to a chromosome $5 \mathrm{q} 12$ reference signal, indicating the presence of one SMN gene on one chromosome 5 and two SMN genes on the other chromosome 5 (Figure 4). These data indicate that all three patients had a total of three SMN genes. FISH analysis does not allow distinction between SMN1 and SMN2. However, based on the above described SSCP data, showing absence of an intact SMN1 exon 7 for patients SE and DG and that of quantitative PCR which provided evidence for one single SMN1 gene (SMN1 value 0.35) for patient PA, we could infer that the patients had one mutated SMN1 gene and two copies of SMN2 and therefore are compound heterozygotes with one SMN1 allele deleted.

\section{Ratio of full length to total SMN2 transcripts}

We performed PCR amplification of cDNA spanning exons 1 to 8 and subsequent DdeI enzyme digestion which separates the SMN2 transcripts from the uncut SMN1 transcripts (Figure 5). Densitometric analysis of PCR products from three independent amplifications showed an average percentage of full length over total SMN2 transcripts of 41.2 and $31.2 \%$ for patients $\mathrm{DG}$ and $\mathrm{ZE}$, respectively. Thus, the two SMN2 genes of the patient with the milder phenotype produce a higher relative amount of full length transcripts.

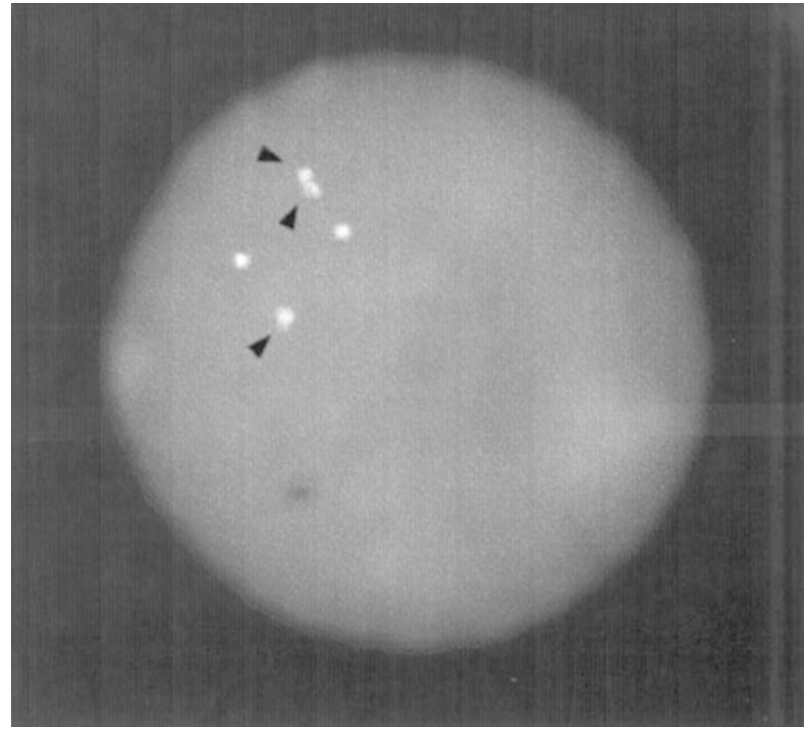

Figure 4 Representative example of FISH analysis. FISH on a $\mathrm{G}_{1}$ interphase nucleus of patient DG. Arrows indicate the SMN signals, the signals close to SMN derive from a chromosome $5 q 12$ reference probe.

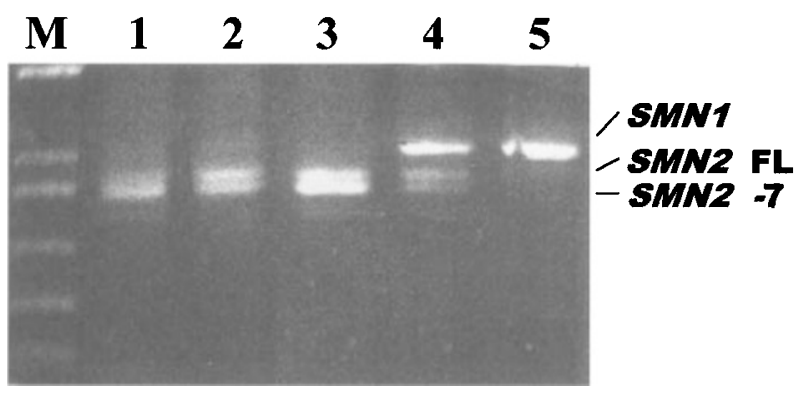

Figure $5 \quad S M N 2$ full length and -7 transcript analysis in lymphoblastoid cells. PCR of cDNA spanning exon 1 to 8 were digested with Ddel to distinguish SMN1 from SMN2 products. Bands corresponding to full length (FL) and - 7 SMN2 transcripts of patient DG (lane 2) were of similar intensity, whereas -7 SMN2 products appear more abundant for ZE (lane 1) and a control SMA type II patient (lane 3). SMN1 products of patients DG and ZE are barely visible, likely due to degradation of the mutated transcripts. Lane 4: normal control, lane 5: control homozygously deleted for the SMN2 gene, M: DNA size marker.

\section{Analysis of gems in fibroblasts}

Immunofluorescence analysis of fibroblasts from patients ZE and DG was performed to determine the number of nuclei containing gems. A significantly higher number of gems was found in the nuclei from both patients compared to that of a type II patient with homozygous absence of SMN1 (-7/-7). In particular, gems were found in approximately 43 and $60 \%$ of nuclei from the type II and type III patient, respectively, compared to only $13 \%$ of nuclei with gems from the control SMA 
patient (CR) and to $71 \%$ from a normal control (FA) (Table 1).

\section{Treatment with aminoglycoside antibiotics suppresses} the stop codon

We tested whether treatment with the aminoglycoside G-418 of fibroblasts and lymphoblastoid cells from the patients with the W102X mutation could suppress the premature termination codon. RT - PCR of mRNA from cultures treated with G-418 for $48 \mathrm{~h}$ showed a decrease in the level of -3 transcripts and an increase in full-length transcripts (Figure 6). Moreover, Western blot analysis showed absence of the $31-\mathrm{kDa}$ protein isoform in the extracts of treated cell cultures suggesting that G-418 suppresses the premature stop mutation which also results in the suppression of exon 3 skipping (Figure 7). This finding provides further evidence that skipping of exon 3 is induced by the mutation. Suppression of exon skipping appeared to be time and dose dependent as indicated by the presence of a small proportion of -3 transcripts in lymphoblastoid mRNA after $48 \mathrm{~h}$ but absence of the corresponding protein isoforms after $72 \mathrm{~h}$, whereas treatment with $100 \mu \mathrm{g} / \mathrm{ml}$ was sufficient to suppress shortened transcripts in fibroblasts within $48 \mathrm{~h}$. Higher doses of G-418 were toxic leading to cell death within 3 days.

\section{Discussion}

We report on three patients with mutations in SMN1 exon 3 which lead to skipping of exon 3 in a proportion of transcripts with conservation of the open reading frame. Several genes have been reported in which mutations producing premature termination codons are associated with skipping of the exon containing the mutation (reviewed by Valentine ${ }^{26}$ ). Whereas alternative splicing involving mainly exons 7 and 5 is a common phenomena for the SMN2 transcripts, to our knowledge this is the first observation of skipping of mutated exons in SMN1 transcripts.

All three patients of the present study have in common a mutation in SMN1 exon 3 and the presence of two SMN2 genes. The most severely affected patient (PA) has a 5-bp deletion (425del5). The same frameshift mutation has been described in a severe case of SMA type I who survived for 42 days. ${ }^{22}$ Based on haplotype analysis we had concluded that this patient had only one single SMN2 gene which we have recently confirmed by semiquantitative PCR analysis. ${ }^{27}$ To our knowledge, only one other patient with a single SMN2 gene has been reported before. This infant had an unusually severe phenotype with reduced foetal movements from 30 weeks of gestation and survived for only 4 days. ${ }^{10}$ The present patient, also a type I, is almost 3 years old and not intubated and, therefore, may be assigned to the less severe end of the type I phenotypic spectrum. ${ }^{28}$ The relatively mild phenotype of this patient compared to the previous one with the same mutation, may likely be ascribed to the presence of one

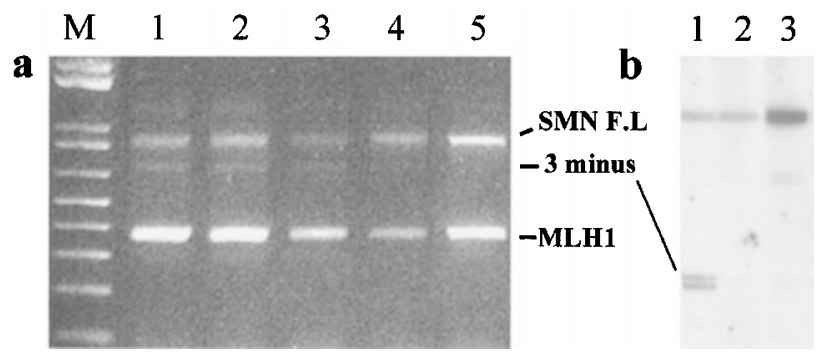

Figure 6 Reduction of -3 transcript isoforms after aminoglycoside treatment. (a) PCR of SMN CDNAs (exons 1-7) and partial MLH1, used as external standard, of mRNA from untreated (lane 1) and G-418 $(50 \mu \mathrm{g} / \mathrm{ml})$ treated lymphoblastoid cells (lane 2) and untreated (lane 3 ) and treated fibroblasts $(100 \mu \mathrm{g} / \mathrm{ml})$ from patient DG (lane 4). Lane 5: control. (b) Lownumber-cycle radioactive PCR of CDNAs of untreated (lane 1), treated fibroblasts $(100 \mu \mathrm{g})$ from patient DG (lane 2) and control (lane 3).

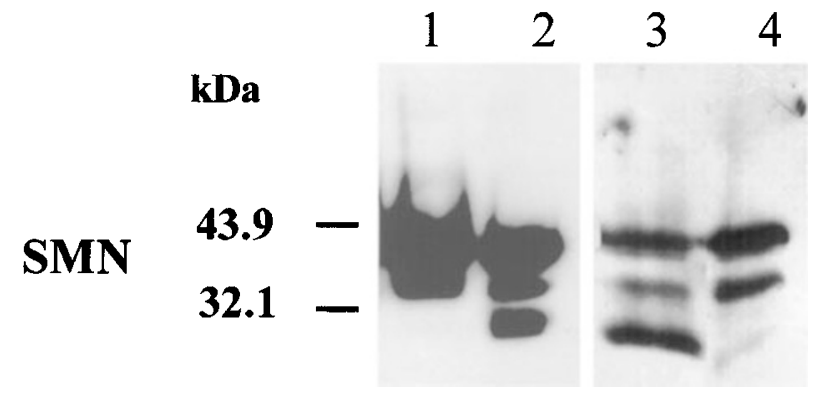

Figure 7 Western blot of SMN protein isoforms extracted from G-418 treated $(50 \mu \mathrm{g} / \mathrm{ml})$ lymphoblastoid cells of patient DG (lane 1) or untreated cells (lane 2) and from fibroblasts incubated with G-418 $(100 \mu \mathrm{g} / \mathrm{ml})$ from patient ZE (lane 4$)$ or control cells (lane 3 ). Treatment with G-418 resulted in disappearance of the shortened protein isoform for both cell types.

Table 1 Germs in fibroblasts

\begin{tabular}{|c|c|c|c|c|}
\hline Individual & Phenotype & $\begin{array}{l}\text { Total no. } \\
\text { cells }\end{array}$ & $\begin{array}{l}\text { Nuclei } \\
\text { with gems }\end{array}$ & $\begin{array}{l}\text { Gems/100 } \\
\text { nuclei }\end{array}$ \\
\hline FA & Normal & 668 & $474(71.0 \%)$ & 126.0 \\
\hline CR & SMA I/II $(-7 /-7)$ & 105 & $14(13.3 \%)$ & 16.2 \\
\hline ZE & SMA II & 469 & $201(42.8 \%)$ & 60.5 \\
\hline DG & SMA III & 566 & $342(60.4 \%)$ & 106.7 \\
\hline
\end{tabular}


additional SMN2 gene. In a previous analysis of the SMN2 copies by FISH in a limited number of patients, we found a copy number of two SMN2 genes associated with a phenotype close to the severe end of the type I group. ${ }^{8}$ It is possible that the clinical phenotype of the present patient, which appeared slightly less severe than may be expected based on the SMN2 copy number alone, is also influenced to some extent by exon skipping in a proportion of SMN1 transcripts. No cell cultures were available to investigate this hypothesis further.

The other two patients (ZE, type II and DG, type III) have a relatively mild phenotype despite the presence of the W102X mutation and only two SMN2 copies. In our previous study, type II and type III patients were found to have three and generally four copies of SMN2, respectively. ${ }^{8}$

We postulated that skipping of the mutated exon could give rise to an incomplete protein isoform which could in part compensate for the low SMN2 copy number. We could show that loss of exon 3 generates in-frame transcripts which are translated in shortened protein isoforms. This is indirectly supported by the disappearance of this isoform in Western blots following suppression of the nonsense codon by treatment of the cells with G-418.

The only point mutation previously identified in exon 3 is a missense mutation, E134K, found in a type I SMA patient. ${ }^{29}$ This mutation severely reduced the ability of SMN to interact with Sm proteins. ${ }^{20}$ However, Mohaghegh et al ${ }^{30}$ have shown that the E134K mutation does not lead to loss of gem formation and is unable to exert a dominant negative effect on the formation of these structures. Consistent with these data is our finding that the fibroblasts of the patients with the W102X mutation form a high number of gems. In a previous study we found gems, on average, in $12.9 \%$ of nuclei of type II patients ${ }^{18}(13.3 \%$ for the control patient in the present study). In contrast, we found gems in 43 and $60 \%$ of the nuclei of the type II and type III patient with the nonsense mutation, respectively. These results may suggest that the -3 protein isoform contributes to SMN protein complex formation in the nucleus and that the SMN tudor domain is not crucial for gem formation. Interestingly, the recently identified Schizosaccharomyces pombe protein Yab8p which shares homology with SMN and does not contain a tudor domain, fulfils a similar function as SMN in the nucleus but not in the cytoplasm. ${ }^{31}$ Thus, we may hypothesize that the in-frame $-3 \mathrm{SMN}$ protein isoform, which may not be functional in the cytoplasm since it is presumably unable to bind Sm proteins, may be partially functional in the nucleus where it participates in the formation of the protein complex. This could consequently moderate the disease phenotype and compensate for the low SMN2 gene copy number.

The particularly mild phenotype of the type III patient is difficult to explain. The only difference between the two patients with the W102X mutation detected at the SMN locus is the second point mutation in exon 3 in the type III patient.
It is unlikely that this mutation contributes to exon skipping since no protein isoform lacking exon 3 was observed after suppression of the nonsense codon by G-418. However, the relative amount of full length SMN2 transcripts appeared higher for the less severely affected patient, compared to that of the type II patient, suggesting reduced exon 7 exclusion in the SMN2 transcripts of the patient with the milder phenotype.

Finally, aminoglycoside G-418 treatment suppressed the premature stop mutation in SMN in cultured cells. Similar findings have recently been reported for nonsense mutations in the dystrophin gene ${ }^{32}$ and the cystic fibrosis transmembrane conductance regulator gene. ${ }^{24}$ Our observation raises the prospect of a treatment for those rare SMA patients with nonsense mutations in the SMN1 gene.

In conclusion, the disease severity of SMA is presumably determined by a combination of a variety of factors. The most important one is the number of SMN2 gene copies. The type of subtle mutation may also be determinant. We propose here that in such rare cases with subtle mutations, skipping of the mutated exons may further modulate the phenotype. Moreover, our finding of differences in the ratio of full length to total SMN2 transcripts supports the hypothesis of a role of modifier genes involved in regulating alternative splicing.

\section{Acknowledgements}

We thank the patients and the Italian Union for Muscular Dystrophies (UILDM) for their kind cooperation. We thank $\mathrm{Dr} G$ Dreyfuss for providing the 2B1 monoclonal antibody. The financial support of Telethon Italy (grant 828) is gratefully acknowledged.

\section{References}

1 Munsat TL, Davies KE: Meeting Report. International SMA Consortium meeting. Neuromusc Disord 1992; 2: 423-428.

2 Lefebvre S, Bürglen L, Reboullet S et al: Identification and characterization of a spinal muscular atrophy-determining gene. Cell 1995; 80: 155-165.

3 Lorson CL, Hahnen E, Androphy EJ, Wirth B: A single nucleotide in the $S M N$ gene regulates splicing and is responsible for spinal muscular atrophy. Proc Natl Acad Sci USA 1999; 96: 6307-6311.

4 Monani UR, Lorson CL, Parsons DW et al: A single nucleotide difference that alters splicing patterns distinguishes the SMA gene SMN1 from the copy gene SMN2. Hum Mol Genet 1999; 8: $1177-1183$

5 Gennarelli M, Lucarelli M, Capon M et al: Survival motor neuron gene transcript analysis in muscles from spinal muscular atrophy patients. Biochem Biophys Res Commun 1995; 213: $342-348$

6 Lorson CL, Androphy EJ: An exonic enhancer is required for inclusion of an essential exon in the SMA-determining gene SMN. Hum Mol Genet 2000; 9: 259-265.

7 Lefebvre S, Burlet P, Liu Q et al: Correlation between severity and SMN protein level in spinal muscular atrophy. Nature Genet 1997; 16: $265-269$.

8 Vitali T, Sossi V, Tiziano F et al: Detection of the survival motor neuron (SMN) genes by FISH: further evidence for a role for SMN2 in the modulation of disease severity in SMA patients. Hum Mol Genet 1999; 8: 2525 - 2532. 
9 Coovert DD, Le TT, McAndrew PE et al: The survival motor neuron protein in spinal muscular atrophy. Hum Mol Genet 1997; 6: $1205-1214$

10 Taylor JE, Thomas NH, Lewis CM et al: Correlation of SMNt and $S M N c$ gene copy number with age of onset and survival in spinal muscular atrophy. Eur J Hum Genet 1998; 6: 467-474.

11 Campbell L, Potter A, Ignatius J, Dubowitz V, Davies KE: Genomic variation and gene conversion in spinal muscular atrophy: implications for disease process and clinical phenotype. Am J Hum Genet 1997; 61: 40-50.

12 Wirth B: An update of the mutation spectrum of the survival motor neuron gene (SMN1) in autosomal recessive spinal muscular atrophy (SMA). Hum Mutation 2000; 15: 228-237.

13 Parsons DW, McAndrew PE, Iannaccone ST, Mendell JR, Burghes AHM, Prior TW: Intragenic telSMN mutations: frequency, distribution, evidence of a founder effect, and modification of the spinal muscular atrophy phenotype by cenSMN copy number. Am J Hum Genet 1998; 63: 1712-1723.

14 Wirth B, Herz M, Wetter A et al: Quantitative analysis of survival motor neuron copies: identification of subtle SMN1 mutations in patients with spinal muscular atrophy, genotype-phenotype correlation, and implications for genetic counseling. Am J Hum Genet 1999; 64: 1340-1356.

15 Liu Q, Fischer U, Wang F, Dreyfuss G: The spinal muscular atrophy disease gene product $\mathrm{SMN}$, and its associated protein SIP1 are in a complex with spiceosomal snRNP proteins. Cell 1997; 90: 1013-1021.

16 Liu Q, Dreyfuss G: A novel nuclear structure containing the survival of motor neurons protein. EMBO J 1996; 15: $3555-$ 3565.

17 Pellizoni L, Kataoka N, Charroux B, Dreyfuss G: A novel function for SMN, the spinal muscular atrophy disease gene product, in pre-mRNA splicing. Cell 1998; 95: 615-624.

18 Patrizi AL, Tiziano F, Zappata S, Donati MA, Neri G, Brahe C: SMN protein analysis in fibroblast, anmiocyte and CVS cultures from spinal muscular atrophy patients and its relevance for diagnosis. Eur J Hum Genet 1999; 7: 301 - 309.

19 Charroux B, Pellizoni L, Perkinson RA, Shevchenko A, Mann M, Dreyfuss G: Gemin3: A novel DEAD box protein that interacts with SMN, the Spinal muscular atrophy gene product, and is a component of gems. J Cell Biol 1999; 147: 1181-1193.

20 Bühler D, Raker V, Lührmann R, Fischer U: Essential role for the tudor domain of SMN in spliceosomal U snRNP assembly: implications for spinal muscular atrophy. Hum Mol Genet 1999; 8: $2351-2357$.
21 Talbot K, Miguel-Aliaga I, Mohaghegh P, Ponting CP, Davies KE: Characterization of a gene encoding survival motor neuron (SMN)-related protein, a consituent of the spliceosome complex. Hum Mol Genet 1998; 7: 2149-2156.

22 Brahe C, Clermont O, Zappata S, Tiziano F, Melki J, Neri G: Frameshift mutation in the survival motor neuron gene in a severe case of SMA type I. Hum Mol Genet 1996; 5: 1971-1976.

23 Van der Steege G, Grootscholten PM, van der Vlies P et al: PCRbased DNA test to confirm the clinical diagnosis of autosomal recessive spinal muscular atrophy (SMA). Lancet 1995; 345 : 985-986.

24 Howard M, Frizzell RA, Bedwell DM: Aminoglycoside antibiotics restore CFTR function by overcoming premature stop muations. Nature Med 1996; 2: $467-469$.

25 Velasco E, Valero C, Valero A, Moreno F, Hernandez-Chico C: Molecular analysis of the SMN and NAIP genes in Spanish spinal muscular atrophy (SMA) families and correlation between number of copies of ${ }^{\mathrm{B}} \mathrm{BCD} 541$ and SMA phenotype. Hum Mol Genet 1996; 5: $257-263$.

26 Valentine CR: The association of nonsense codons with exon skipping. Mutation Res 1998; 411: 87-117.

27 McAndrew PE, Parsons DW, Simard LR et al: Identification of proximal spinal muscular atrophy carriers and patients by analysis of $\mathrm{SMN}^{\mathrm{t}}$ and $\mathrm{SMN}^{\mathrm{c}}$ gene copy number. Am J Hum Genet 1997; 60: $1411-1422$.

28 Dubowitz V: Chaos in the clasification of SMA: A possible resolution. Neuromusc Disord 1995; 5: 3-5.

29 Clermont O, Burlet P, Cruaud C et al: Mutation analysis of the SMN gene in undeleted SMA patients. Am J Hum Genet 1997; 61: A329.

30 Mohaghegh P, Rodrigues NR, Owen N et al: Analysis of mutations in the tudor domain of the survival motor neuron protein SMN. Eur J Hum Genet 1999; 7: 519-525.

31 Hannus S, Bühler D, Romano M, Seraphin B, Fischer U: The Schizosaccharomyces pombe protein Yab8p and a novel factor, Yip1p, share structural and functional similarity with the spinal muscular atrophy-associated proteins SMN and SIP1. Hum Mol Genet 2000; 9: 663-674.

32 Barton-Davies ER, Cordier L, Shoturma DI, Leland SE, Sweeney HL: Aminoglycoside antibiotics restore dystrophin function to skeletal muscles of mdx mice. J Clinic Invest 1999; 104: 375 381. 